\title{
Production of prodigiosin from Serratia marcescens isolated from soil
}

\author{
N. Sundaramoorthy ${ }^{1}$, P. Yogesh ${ }^{2}$ and R. Dhandapani ${ }^{3^{*}}$ \\ ${ }^{1}$ Dept. of Microbiology, Adhiparasakthi College of Arts \& Science, Kalavai-632 506, TN, India \\ ${ }^{2}$ Microgeneics, Gandhi Nagar, Vellore-632 006; ${ }^{3}$ Dept. of Microbiology, Periyar Univ., Salem-636 011, TN, India \\ danpani@gmail.com*
}

\begin{abstract}
Prodigiosin is a promising drug owing to its reported characteristics of having antifungal, immunosuppressive and anti-proliferative activity. Prodigiosin was first characterized from Serratia marcescens. Investigations were made in the present study to screen new strains of Serratia that effectively produce prodigiosin. A new strain designated as $\mathrm{S}$. marcescens NY1 was isolated. The parameters viz., temperature, $\mathrm{pH}$, sugar substrate and oil substrate were optimized to increase the production of prodigiosin. It was observed that maximum amount of prodigiosin was produced at temperature $30^{\circ} \mathrm{C}$ and $\mathrm{pH}$ 7.0. Among the different sugar substrates tested maltose when amended in the medium yielded $425 \pm 40 \mathrm{mg} / \mathrm{L}$ of prodigiosin. Oil substrates play a vital role in prodigiosin production. Among the various oil substrates used the production of prodigiosin was maximum $(535 \pm 45 \mathrm{mg} / \mathrm{L})$ when the medium was amended with peanut oil.
\end{abstract}

Keywords: Prodigiosin, Serratia marcescens, biopigments Introduction

Natural products represent one of the critical sources of chemical diversity and potential medicinal use. Pigments produced by organisms as reminiscence of its secondary metabolism are commonly referred as biopigments. These biopigments have wide synthetic and commercial application (Shirata et al., 2000). Prodigiosin a red pigment produced by many strains of the bacterium like Serratia marcescens and some other unrelated microbial strains, such as Vibrio psychroerythrus, Streptomycin griseoviridis and Hahella chejuensis was found to exhibit antibacterial, antimycotic, immunomodulating, anti-tumor and anti-malarial properties (Frustner, 2003). Demain et al., (1995) has reported that prodigiosin revealed a broad range of inhibitory activities against many bacterial, fungal and protozoan species while he tested these organism against the naturally produced anti microbial products.

Prodigiosin induced apoptosis in cancer cell lines by the characteristic DNA laddering pattern and condensed nuclei or apoptotic bodies were reported (Beatriz, 2000). Williamson et al., (1992) had reported that sequencing and heterologous expression of the pig cluster responsible for prodigiosin biosynthesis in two Serratia sp. Srijith (2006) suggested that it is possible to genetically transform the enzymes responsible for prodigiosin production from Serratia marcescens to Bacillus subtilis.

The present study focuses on screening new strains of Serratia that produces prodigiosin and to optimize the culture medium for effective pigment production.

Research article

CIndian Society for Education and Environment (iSee)

"Prodigiosin"

http://www.indjst.org

\section{Materials and methods}

Soil samples were collected from different parts of Yercaud hills and screened for Serratia marscescens. The collected soil samples were serially diluted and plated on nutrient agar plates. Red-pigmented colonies were isolated from the plates after incubation and preserved at $4^{\circ} \mathrm{C}$. The isolated colonies were identified based on Bergey's classification of determinative bacteriology.

A loopful of culture was inoculated in pre-sterilized $100 \mathrm{ml}$ nutrient broth. The flask was kept in a shaker at $120 \mathrm{rpm}$ for $16-18 \mathrm{~h}$ at $30^{\circ} \mathrm{C}$. The culture broth was centrifuged at $10,000 \mathrm{rpm}$ for $20 \mathrm{~min}$. Cell suspension was prepared using sterile distilled water and adjusted to 0.2 OD using UV Visible spectrophotometer. One percent $\left(10^{5} \mathrm{CFU} / \mathrm{ml}\right)$ of the above suspension was used as inoculum for the production of Prodigiosin. The bacterial isolate was subcultured in $100 \mathrm{~mL}$ of nutrient broth and incubated in a rotary shaker for $48 \mathrm{~h}$ at $37^{\circ} \mathrm{C}$.

Estimation of Prodigiosin (Slater et al., 2003)

The organisms were harvested by centrifuging at $10,000 \mathrm{rpm}$ for 10 minutes. The supernatant was discarded and the pellet was resuspended in acidified ethanol (4\% of $1 \mathrm{M} \mathrm{HCl}$ in $96 \mathrm{~mL}$ ethanol). The mixture was vortexed and the suspension was centrifuged at $10,000 \mathrm{rpm}$ for 10 minutes. The supernatant was transferred to a fresh vial and observed under UV-visible spectrophotometer at $534 \mathrm{~nm}$. The prodigiosin produced was quantified using known concentrations of prodigiosin. Effect of temperature on pigment production

Equal volume of the bacterial isolate was inoculated in nutrient broth and incubated at different temperature viz., $25,30,35$ and $40{ }^{\circ} \mathrm{C}$ for $48 \mathrm{~h}$. The prodigiosin production was estimated after incubation. The temperature at which maximum production of prodigiosin was observed was chosen and maintained in the following studies.

\section{Effect of initial $\mathrm{pH}$ on pigment production}

Equal volume of the bacterial isolate was inoculated in nutrient broth with various initial $\mathrm{pH}$ viz., 6.5, 7.0, 7.5 and 8.0. The flasks were incubated at $30^{\circ} \mathrm{C}$ for $48 \mathrm{~h}$. The prodigiosin production was estimated after incubation. The initial $\mathrm{pH}$ at which maximum production of prodigiosin was observed was chosen and maintained in the following studies.

Effect of different sugar substrate on pigment production

To study the effect of different sugars, as substrate on pigment production the isolate was cultivated in the presence of different sugars viz., maltose, glucose, lactose and sucrose $(2 \%)$ in nutrient broth. The $\mathrm{pH}$ of the 
broth was adjusted to 7.0. Fresh-pigmented culture (5\%) was added to each of the broth. The flasks were then incubated at $30^{\circ} \mathrm{C}$ for 48 hours. After incubation the amount of prodigiosin produced in each medium was estimated.

Effect of different oil substrate on pigment production

The effect of different oil substrates on pigment production were tested by adding $2 \%$ peanut oil in $50 \mathrm{ml}$ nutrient broth, $2 \%$ sesame oil in $50 \mathrm{ml}$ nutrient broth, $2 \%$ coconut oil in $50 \mathrm{ml}$ nutrient broth and $2 \%$ neem oil in $50 \mathrm{ml}$ nutrient broth. The $\mathrm{pH}$ was adjusted to 7.0. Fresh-pigmented culture (5\%) was added to each of the broth.
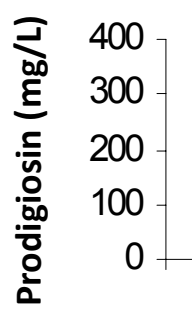

bacterial isolate was cultivated at different temperature and the amount of prodigiosin was maximum at $30^{\circ} \mathrm{C}$ (Fig. 1). The influence of initial $\mathrm{pH}$ of the growth medium on prodigiosin production was investigated. The prodigiosin production was maximum at pH 7.0 (Fig. 2).

The influence of sugar substrates (maltose/ glucose/lactose/ sucrose) in the growth medium on prodigiosin production was elucidated. The production was maximum in the presence of maltose. Moderate level of pigment production was observed in medium amended with lactose and sucrose. The presence of glucose in the medium

Fig. 1. Effect of temperature on Prodigiosin production in S. marcescens did not increase the
The cultures were incubated at $30^{\circ} \mathrm{C}$ for 48 hours. After incubation the amount of prodigiosin produced in each medium was estimated.

All the experiments were conducted in triplicates unless otherwise stated. Data points in tables and figures represent means, with all error bars shown $( \pm 1$ standard error of mean). Both mean and standard deviation performed were appropriate, using the statistical package on Microsoft ${ }^{\circledR}$ Excel version 2003.

Results

Twenty soil samples were collected from different parts of Yercaud hills and screened for prodigiosin producing organism. Among the 20 soil samples Redpigmented colonies were isolated from 5 soil samples. The isolated colonies were identified based on their morphology and biochemical characteristics. The isolates were confirmed as Serratia marcescens.

The amount of prodigiosin produced by the 5 bacterial isolates was estimated. Among the 5 the yield was found to be more in 1, which was designated as Serratia marcescens NY1. This isolate was taken for further cultivation under submerged fermentation and the amount of prodigiosin was found to $335 \pm 10 \mathrm{mg} / \mathrm{L}$. The
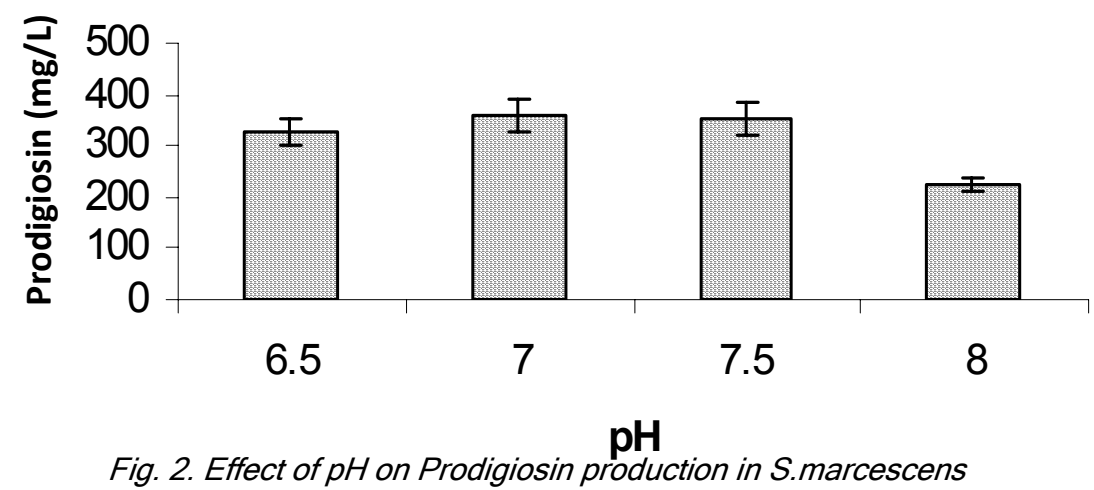

Research article

COIndian Society for Education and Environment (iSee)

"Prodigiosin"

http://www.indjst.org production of prodigiosin (Fig 3).

Effect of different oil substrates on pigment production

The bacterial isolate was cultivated in medium amended with peanut, sesame, coconut and neem oil. It was observed that maximum amount of prodigiosin resulted in the medium supplemented with peanut oil followed by sesame oil, coconut oil and neem oil (Fig 4).

Discussion

Biopigments produced by bacteria possess enormous efficiency as medicinally important products. Prodigiosin, a red pigment, belongs to the family of tripyrrole was found to exhibit antibacterial, antimycotic, immunomodulating, anti-tumor and anti-malarial properties. These pigments were found associated with the cell wall vesicle of the bacteria. The present investigation centered on isolation of prodigiosin producing organisms from soil and formulating a production medium for effective production of prodigiosin.

The bacterial isolate elaborated the pigment at $30^{\circ} \mathrm{C}$ and the rate was reduced as the temperature increases. Williams \& Hussain Quadri (1980) reported that no prodigiosin was produced when cultures were incubated at $38^{\circ} \mathrm{C}$; however pigment production was observed when the temperature was shifted to $27^{\circ} \mathrm{C}$. A complete block in prodigiosin was observed in most of the basically used media tested at $37^{\circ}$ $\mathrm{C}$ was similar to the result observed by Pryce \& Terry (2000).

While considering the basic role of carbon source in augmenting the pigment production, the addition of maltose or sucrose or lactose was shown to enhance the prodigiosin yield and addition of glucose was found to be ineffective. Anna R Oller (2005) reported that glucose and sorbitol had a repressive effect on prodigiosin synthesis. Chang et al., (2000) has reported $3 \mathrm{mg} / \mathrm{ml}$ of prodigiosin when dextrose 


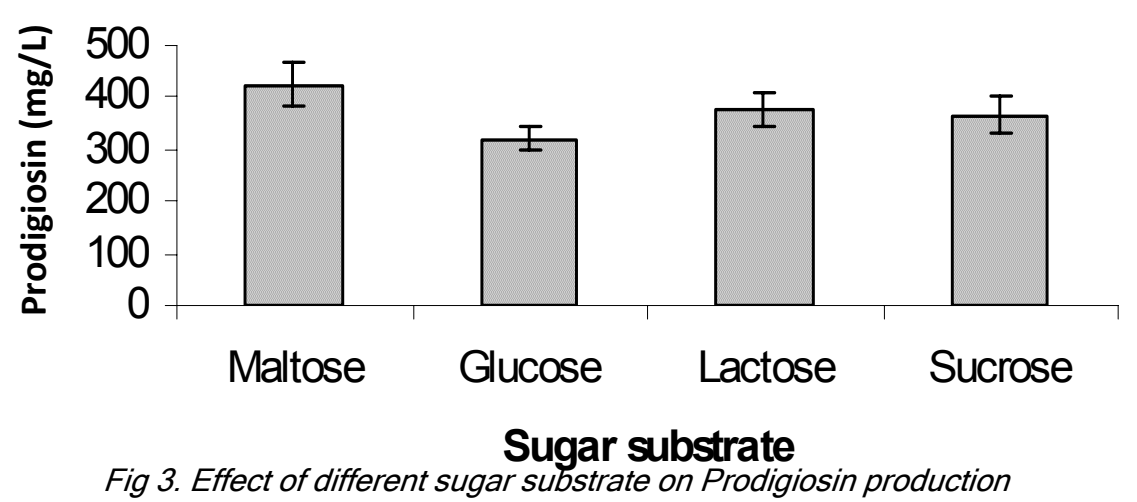

Fig 3. Effect of different sugar substrate on Prodigiosin production

isolated from soil. BMC Microbiol. 4, 110.

3. Beatriz $M$, Navarro $S$, Pique $M$, Vilaseca M, Martinell M, Giralt E, Gil J and Peroz-Tomas R (2000) Prodigiosin from the supernatant of Serratia marcescens induce apoptosis in haematopoietic cancer cell lines. Brit. $J$ .Pharmacol. 131, 585-593.

4. Chang S, Sanada M, Johdo O, Ohta S, Nagamatsu $Y$ and Yoshimoto A (2000) High production of prodigiosin by Serratia marcescens grown on ethanol. Biotechnol. Lett. 22, 1761-1765.

was used in the medium. Jungdon et al., (2001) reported that in a bioreactor study with an internal absorbent for prodigiosin, the final yield was $13 \mathrm{mg} / \mathrm{ml}$ in which dextrose was used in the culture broth.

The suitable fatty acid for pigment production was optimized by cultivating the bacterial isolate in the presence of peanut, sesame, coconut and neem oil. In the case of fatty acid alternatives, peanut oil broth gave a maximum yield $(\sim 560 \mathrm{mg} / \mathrm{l})$ and this result was compared with the existing literatures that uses different carbon source. The observed enhancement in the yield of prodigiosin in peanut oil has been attributed to its higher saturated fatty acid content. On the other hand, sesame oil broth contains a higher level of unsaturated fatty acid (approx. 47\%) than the rest. From these arguments it was speculated that the bonded fatty acids are of limited carbon source and less accessible by $S$. marcescens. Giri et al., (2004) reported peanut seed powder increased the production of prodigiosin and they have concluded that the saturated form of fatty acid plays a role in enhanced cell growth and prodigiosin production.

Reference

1. Anna R. Oller (2005) Media effects of sugars on pigmentation and antibiotic susceptibility in Serratia marcescens. Sci. \& Technol., Transac. of Missouri Acad. Sci. 243-246.

2. Giri V. Anuradha, Nandhini Anandkumar, Geetha muthukumaran and Gautham pennathur (2004) A novel medium for the enhanced cell growth and production of prodigiosin from Serratia marcescens

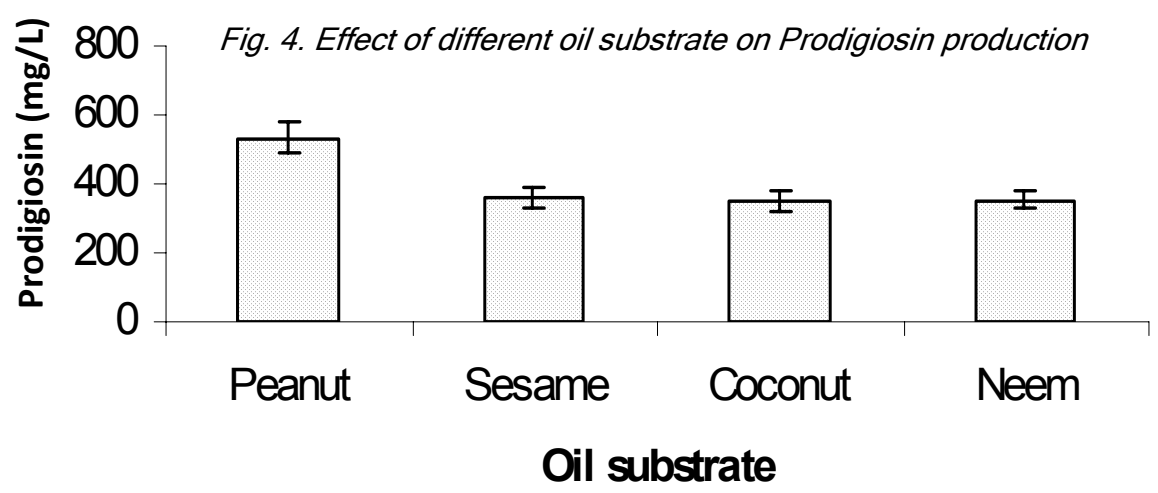

CIndian Society for Education and Environment (iSee)
Research article
"Prodigiosin"

http://www.indjst.org
5. Demain AL (1995) In fifty years of antimicrobials: past perspectives and future trends (Eds. Hunter PA, Darby GK \& Russel NJ), Soc. for Gen. Microbiol., Cambridge, 205-228.

6. Frustner A (2003) Chemistry and Biology of roseopniun and the prodigiosin alkaloids: a survey of the last 2500 years. Angew. Chem. Int. Ed. Engl. 42, 3582-3603.

7. Jungdon $B$, Hyunsoo $M$, Kyeong-Keun $O$, Chang-Ho K, Dae SL, Seung WK and Suk-In H (2001) A novel bioreactor with an internal adsorbent for integrated fermentation and recovery of prodigiosin like pigment produced from Serratia sp. Biotechnol. Letts. 23, 1315-1319.

8. Pryce LH and Terry FW (2000) Spectrophotometric assay of gene expression: Serratia marcescens pigmentation. Bioscene. 26, 3-13.

9. Shirata A, Tsukamoto $P$, Yasui $H$, Hata $T$, Hayasaka S, Kojima A and Kato H (2000) Isolation of bacteria producing bluish purple pigment and use for dyeing. JARQ. 34, 131-140.

10. Slater H, Crow M, Everson L and Salmond GP (2003) Phosphate availability regulates biosynthesis of two antibiotics, prodigiosin and carbapenem in Serratia via both quorum sensing- dependent and independent pathway. Mol. Microbiol. 47, 303-320.

11. Srijith VM (2006) Analysis of Serratia marcescens genome - identifying the biosynthetic pathway of the pigment prodigiosin -a computational approach. Centre for Bio Informatic, Kerala Univ.

12. Williams $P$, Bainton NJ, Swift $S$, Chhabra SR, Winson MK, Stewart GSAB, Salmond GPC and Bycroft BW (1992) Small molecule mediated density dependent control of gene expression in prokaryotes: bioluminescence and the biosynthesis of carbapenem antibiotics. FEMS Microbiol. Lett. 100, 161-168.

13. Williams RP and Hussain Quadri SM (1980) The pigment of Serratia. CRC press, Bocaraton, USA. pp: 31-75.
Sundaramoorthy et al. Indian J.Sci.Technol. 